\title{
A New Semantics for Number
}

\author{
Uli Sauerland \\ Tübingen University
}

Research on the semantics of number has been strongly influenced by the distribution of overt number morphology in English. As is well know, number can be expressed on nouns and on verbs in English. In example (1), overt plural morphology is present in both places.

$$
\text { The books-[PL] were-[PL] lying on the table. }
$$

All research on plurality has assumed the the [Pl]-feature on the noun is interpreted in some way. Bennett (1974) was the first to propose a semantics of number along these lines, and this assumption has been adopted by all subsequent research. Furthermore most research has followed Bennett to assume that the [PI]-feature on the verb remains uninterpreted in English, and is a reflex of syntactic agreement with the subject. ${ }^{1}$ A contemporary version of Bennett's proposal (e.g. Chierchia 1998b, Schwarzschild 1996) assigns to the singular noun book a set of individuals as its extension, while the extension of the plural noun books includes groups of these individuals (and, for Schwarzschild, atomic individuals, as well). These denotations are illustrated in (2): ${ }^{2}$

$$
\begin{array}{ll}
\text { a. } & \llbracket \mathrm{book} \rrbracket=\{\mathrm{a}, \mathrm{b}, \mathrm{c}\} \\
\text { b. } & \llbracket \mathrm{books} \rrbracket=\{\mathrm{a} \oplus \mathrm{b} \oplus \mathrm{c}, \mathrm{a} \oplus \mathrm{b}, \mathrm{a} \oplus \mathrm{c}, \ldots\}
\end{array}
$$

However, in many languages, overt plural morphology is also found on the determiner as shown by the German example (3a). Even in English plurality is also expressed on demonstrative determiners as in (3b).
a. Die Bücher lagen
auf dem Tisch. (German)
the-[Pl] books-[Pl] were lying-[PI] on the table
b. These books were lying on the table. (English)

Such facts indicate that other options should be considered for the question of determining which $[\mathrm{Pl}]$ features have semantic content.

In this paper, I will argue that even German does not express morphologically the [Pl]-feature that is interpreted. I propose that there is another syntactic head above the determiner, which I call the $\phi$-head, and that the only semantically contentful number features are contained in this head. Furthermore, I will argue that $[\mathrm{Pl}]$ on nouns is not interpreted, but is a reflex of syntactic agreement with a $\phi$-head, just like [Pl] on adjectives, verbs, and determiners. There have to be two agreement processes, one to establish agreement in the DP between N, A, D, and the $\phi$-head. The other one to establish agreement between the finite verb and a $\phi \mathrm{P}$ in the subject position.

I first present my proposal in all detail, and then present two arguments 
for presuppositional account of number (Sections 2 and 3). In Section 4 and 5, I account for number marking with quantifiers and indefinites respectively. Sections 6 and 7 extend the proposal to other agreement features. Section 8 is the conclusion.

\section{The Proposal}

Consider first the syntactic properties of the $\phi$-heads, which I claim host the semantically contentf ul agreement features. I assume that $\phi$ in English and German selects for a DP as its complement. This is illustrated in (4):

the book

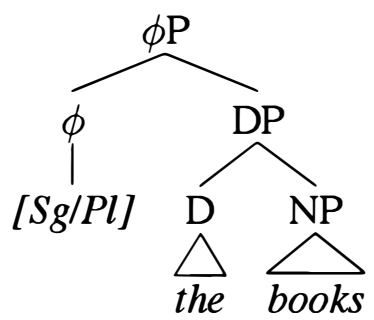

Syntactically any $\phi$-head can combine with any DP regardless of its feature content. The number features of the $\phi$ head are licensed solely by the semantics. The number features on the $\phi$-head, however, license uninterpreted number features in other places via syntactic agreement. In English and German, we find agreement between the noun, the determiner, and the $\phi$-head, as well as between verbal inflection (T) and the $\phi$-head of the subject.

The need to license uninterpreted number features by agreement predicts a specific distribution of $\phi$-heads in English and German. Namely, any DP must be embedded below a $\phi$ head for the agreement requirements of $\mathrm{N}$ and D. Furthermore, any $\mathrm{T}$ requires a $\phi \mathrm{P}$ in its specifier to satisfy its agreement requirements. I will assume that there are some locality conditions on syntactic agreement that predict that DPs must actually be the sister of a $\phi$-head. For DP-coordinations in subject position, then, these conditions predict the distribution of $\phi$-heads illustrated in (5).

Kai and Lina are playing together.

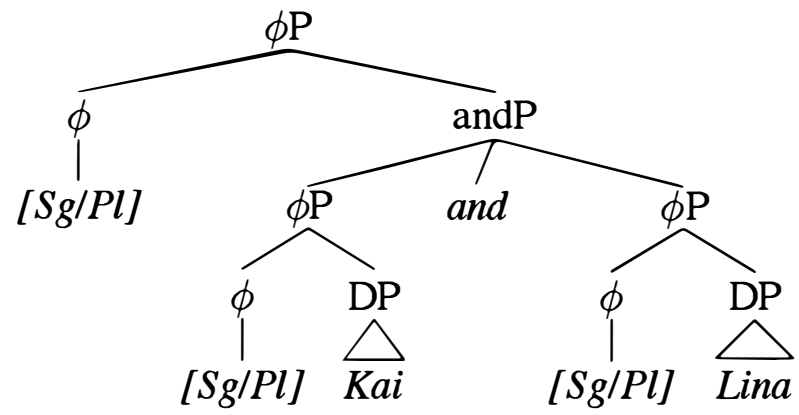

Now consider the semantic licensing of the feature content of $\phi$. I assume that the agreement features in $\phi$ are always interpreted as presuppositions. Specifically, I propose that $[\mathrm{Sg}]$ expresses the presupposition "my sister denotes an atom 
or a mass", while I assume that [Pl] has no inherent presupposition. More formally, I assume the lexical entries in (6): ${ }^{3}$

$$
\begin{array}{ll}
\text { a. } & \llbracket \mathrm{Sg} \rrbracket=i d_{\left\{x \in D_{e} \mid \neg \exists a(\operatorname{atom}(w)(a) \wedge a \sqsubset x \wedge a \neq x)\right\}} \\
\text { b. } & \llbracket \mathrm{Pl} \rrbracket=i d_{D_{e}}
\end{array}
$$

On this proposal, the distribution of $[\mathrm{Pl}]$ is not constrained by an inherent presupposition. It is, however, predicted to be constrained by the general maxim Maximize Presupposition that Heim (1991) argues for. This pragmatic maxim claims that, of two lexical items, which lead to the same truth conditions in all cases where both of their presuppositions are satisfied, the item with stronger presuppositions must be used. For the case of presuppositional agreement features, the maxim therefore predicts the condition in (7):

(7) Use the most specific agreement feature possible whose presupposition is satisfied.

One application of this principle is in (8). (7) blocks (8a) because instead of the presupposition-less [Pl]-feature the more specific, presuppositional $[\mathrm{Sg}]$ feature can be used in this sentence. Then $[\mathrm{Sg}]$ must be used to satisfy (7).

a. ${ }^{*}$ John are here.

b. John is here.

The semantic definition of the $[\mathrm{Sg}]$-feature raises the question of what exactly is an atom? While in most cases this seems very clear (e.g. that John in (8) is an atom), there are some cases are not fully specified by the semantics. For example, Bloomfield apparently remarked that 'Pants are singular on one end, and plural on the other.' In the borderline cases, factors I do not fully understand decide whether something is an atom or not. English consistently choses the plural, while German uses the singular, in the following:

(9) a. English: the scissors, the pliers, the pants

b. German: die Schere, die Zange, die Hose

My proposal predicts that such inherent units of two into a single individual should be a grey area of number licensing. Another such grey area are group denoting nouns like committee and team. The factors determining atomicity in these cases should maybe be called conventions, and are not directly part of my semantic licensing. Whatever the status of these conventions, I believe will not affect my discussion in the following. 


\section{Coordinations and Pronouns}

\subsection{The Number Feature of Coordinations}

The evidence from coordination and pronouns in this section shows that the presuppositional number features I propose are needed to explain the distribution of plural agreement on the verb. ${ }^{4}$ Consider first the coordination in (10) (repeated from (5)).

Kai and Lina are playing.

Because Kai and Lina are two atoms while their mereological sum (the denotation of the coordination) is not, the only number features that are semantically licensed are the following:

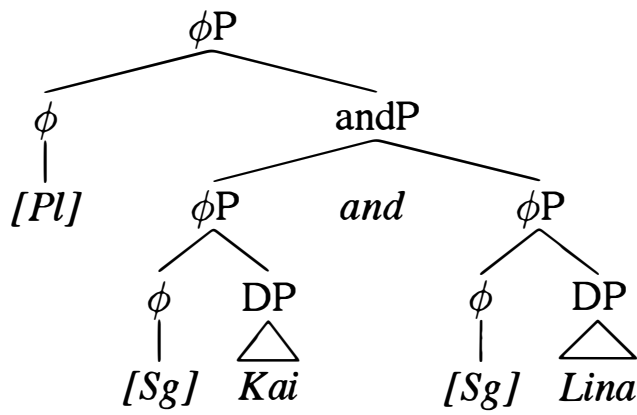

On my proposal, the plural feature of the coordination is licensed as a presupposition on the individual denoted by the coordination. I do not see an alternative to this proposal: Because each conjunct is singular, the [Pl]-feature could not be percolated up in some syntactic fashion from the conjuncts. Another attempt I have seen proposed is that the conjunction and has inherently a [Pl]-feature (Vanek 1977). However, that proposal cannot explain why singular agreement is possible in cases like (11):

(11) a. Strawberries and cream is on the menu.

b. Beans and rice is a basic staple around here.

Singular agreement with a conjunction seems possible when the denotation of the conjunction can be viewed as an atomic individual; specifically, a dish in (11). With the indefinites in (11a), this condition should predict that the combination of [Sg] with [Strawberries and cream] presupposes that the combination of some strawberries and some cream yields an atomic individual. Indeed this will be the prediction from the account of indefinites I present in Section 5 below.

Two similar examples that do not involve indefinites are given in (12). The use of a collective predicate, marginally allows singular agreement, and there is a clear contrast with (10) above. My proposal predicts this behavior because in (12) it is salient to regard the subject's denotation as an atom.

a. 'Kai and Lina makes a good combination.

b. ?Tim and Sarah is a nice couple. 


\subsection{Pronouns}

A second case, where agreement features must be interpreted as presuppositions are (unbound) pronouns. ${ }^{5}$ This proposal goes back to Cooper (1983). Cooper's proposal for pronouns is a special case of my proposal for all DPs. Specifically, I assume that the structure of 'they' $\mathrm{i}_{\mathrm{i}}$ ' is the following:

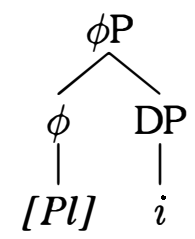

The index $i$ is interpreted as the value the context dependent assignment function provides for index $i$. The number morphology in $\phi$ introduces a presupposition on the context. Namely, in (12) it must be non-atomic.

The non-atomicity presupposition is, in fact, on my proposal derived indirectly from Heim's (1991) Maximize Presupposition. The proposal predicts that the non-atomicity presupposition will only be present if singular pronoun he/she/it is not blocked by some independent factor. This aspect of my proposal is corroborated by the following facts where the non-atomicity presupposition is absent.

In English, consider cases like (13), which are at least in some dialects of English acceptable. In these dialects, the singular pronouns are blocked in cases where the gender of the individual talked about is unknown.

Some student left their umbrella.

A more frequent reason a singular pronoun is blocked is for politeness. For example, it is impolite to address a stranger, especially an older one, by using the second person singular in many languages. In French, the second person plural vous is used instead of the singular in such a situation. In German, usually the third person plural is used as the polite form and the second person plural could only be used for royalty. Consider the German data in (14):

a. Könnten Sie bitte etwas rücken!

could they please a little move

b. Eure Majestät haben euren Silberlöffel geschluckt. your majesty have your silver spoon swallowed

My proposal allows the use of the plural form in examples like (14) since in these cases a politeness consideration blocks the use of the singular, and therefore the Heim's maxim is satisfied by the use of the plural which has no inherent presupposition. Since I argue in section 6 that the third Person features is like [Pl] without inherent presupposition, the shift from second to third person in (14a) can be explained in the same way.

My proposal predicts that generally if a language has politeness constraints on pronoun use, the forms that should surface as the polite forms should be those 
with a less specific inherent presupposition. Specifically, as polite forms replacing the second person singular, only be the second and third person plural and the third person singular should be possible. Tilman Berger (p.c.) points out that Head (1978), which I unfortunately was unable to consult so far, claims that there is indeed such a generalization concerning politeness phenomena.

\section{Definites}

While the arguments in the previous section established that there are presuppositional number features with the interpretation that I propose, this section seeks to establish that number marking on nouns cannot be consistently interpreted.

Consider first two accounts of number marking on definites: the standard proposal (Bennett 1974, Link 1983, Verkuyl 1981 and others) and my proposal. The fact I would like to consider is (15):

The students wrote a paper.

Plural semantics always requires some version of a distributivity operator. I adopt one proposal here for concreteness, though I believe that for my present purposes nothing will depend on the details. I assume that the distributivity operator applies to one-place predicates and is syntactically represented as a $*$. The semantics of the *-operator is given in (16) with the auxiliary concept Cover defined in (17).

$$
* P(X)=1 \text { iff. there is a cover } C \text { of } X \text { with } P(x)=1 \text { for every } x \text { in } C
$$

$$
\text { A set of individuals } C \text { is a Cover for } X \text { iff. } \oplus C=X
$$

The *-operator can apply to NP and VP equally. For example, if the denotations of NP and VP were as in (18a) and (18c), the denotations of the starred predicates are as in (18b) and (18d).

$$
\begin{array}{ll}
\text { a. } & \llbracket \text { student } \rrbracket=\{\text { Tom, Tina, Tanja }\} \\
\text { b. } & \llbracket * \text { student } \rrbracket=\{\text { Tom, Tina, Tanja, Tom } \oplus \text { Tina, Tom } \oplus \text { Tanja, Tina } \oplus \text { Tanja, } \\
& \text { Tom } \oplus \text { Tina } \oplus \text { Tanja }\} \\
\text { c. } & \llbracket \text { wrote a paper } \rrbracket=\{\text { Tom, Tom } \oplus \text { Tina, Tanja }\} \\
\text { d. } & \llbracket *(\text { wrote a paper }) \rrbracket=\{\text { Tom, Tanja, Tom } \oplus \text { Tina, Tom } \oplus \text { Tanja, } \\
& \text { Tom } \oplus \text { Tina } \oplus \text { Tanja }\}
\end{array}
$$

The standard proposal claims that plurality on the noun is interpreted as the *operator. Hence, (18b) is the denotation of the students. The definite determiner selects the maximal element from this set, the group of Tom, Tina, and Tanja. On the VP, on the other hand, the *-operator has no morphological reflex according to the standard theory. Hence, (18d) is a possible interpretation of the VP. Since (18d) has the group of all three students as one of its elements, the standard proposal predicts (15) to be true. Moreover it predicts that the singular could not be used 
in this scenario because (18a), the denotation of the singular noun according to the standard proposal, has no maximal element.

Why can (15) not be used in a situation with just one student? The definition of the * in (16) predicts that student and *student have the same interpretation if there is only one student. ${ }^{6}$ Therefore, the standard approach appeals to a pragmatic condition similar to the one my approach relies on: Do not use the plural if the resulting meaning is identical to the meaning of the singular in the present context.

Now consider my proposal for (15). On my proposal, the *-operator can be applied to any predicate and is never pronounced. In the scenario characterized by (17), the *-operator must apply to the noun since otherwise the set denoted by the NP has no maximal element, and the definite determiner presupposes the existence of such a maximal element. The result of combining the with (18b) is again the group of all three students. Because this is a non-atomic individual the $\phi$-head above the definite determiner cannot contain the feature $[\mathrm{Sg}]$, and therefore must contain [Pl]. Syntactic agreement between $\phi$ and the noun predicts then that only the plural noun form as in (15) is possible in this scenario.

If, however, there is only a single salient student, the complement of $\phi$ would denote this single atomic individual. In such a situation, the presupposition of $[\mathrm{Sg}]$ would be satisfied, and therefore the [Pl]-feature would be blocked by Heim's maxim (7). In this way, my account predicts the (15) cannot be used when there is only one student.

In sum, both proposals provide accounts for the interpretation of (15) that are of roughly equal complexity. Now consider examples that allow a cumulative interpretation of the noun:

(19) a. The daughters of the defense players/Bill and James ...

b. The residents of these cities ...

c. The winners of a gold medal at the 1992 and 1996 olympics ...

Beck (2000) argues that the *-operator alone cannot predict the correct semantics for these examples. Consider the interpretation that arises from applying the * operator to the NP of (19a) as in (20). The denotation of (20) is the maximal group of females that are the daughter of Bill and also the daughter of James, which is certainly not the salient interpretation of (19a).

the *(daughter of Bill and James)

The salient interpretation of (19) involves cumulation of the predicate daughter as in (21). I adopt an account of cumulation based on the **-operator (Krifka 1986, Sternef eld 1998, Beck and Sauerland 2000). The result of cumulation is shown in (21):

** daughter $(X)(Y)=1$ iff. there are both

a. a cover $C_{X}$ of $\mathrm{X}$, such that $\forall x \in C_{X} \exists y \sqsubseteq Y$ : daughter $(x)(y)=1$,

b. $\quad$ and a cover $C_{Y}$ of $Y$, such that $\forall y \in C_{Y} \exists x \sqsubseteq X: \operatorname{daughter}(x)(y)=1$. 
In the concrete scenario of (22a), cumulation of the daughter relation adds one pair to the relation as shown in $(22 b)$.

$$
\begin{array}{ll}
\text { a. } & \text { daughter }=\{\langle\mathrm{DB}, \mathrm{Bill}\rangle,\langle\mathrm{DJ}, \text { James }\rangle\} \\
\text { b. } & * * \text { daughter }=\{\langle\mathrm{DB}, \mathrm{Bill}\rangle,\langle\mathrm{DJ}, \text { James }\rangle,\langle\mathrm{DB} \oplus \mathrm{DJ}, \text { Bill } \oplus \text { James }\rangle\}
\end{array}
$$

Hence, the expression in (23) predicts the right interpretation for Beck's example, namely the group of all females that are either the daughter of Bill or the daughter of James.

$$
\text { the }[* * \text { daughter }](\text { Bill } \oplus \text { James })
$$

Note that (23) does not require the distributive *-operator; the cumulative **-operator is sufficient. Plurality in (23) can therefore not be interpreted as the *-operator. Beck (2000) suggests that the [Pl]-feature on nouns is ambiguous between the * operator and the $* *$-operator, and that furthermore the $* *$-operator when it applies to nouns must be morphologically realized as plural morphology.

Beck's proposal, however, cannot account for examples like (24) where a singular noun allows a cumulative interpretation. For example, (24a) can be used in a situation where the def ense players have no common daughter. (I provide a full account of (24) on my proposal in the next section.)

a. Every daughter of the defense players is watching the game.

b. Every winner of a gold medal at these events can be proud.

c. Every resident of these cities has a bicycle.

I conclude therefore that the standard account of plurality cannot predict why a cumulated noun in a definite description must be plural.

My account, on the other hand, predicts this fact straightforwardly: I assume that the ${ }^{* *}$-operator just like the *-operator is always silent and can apply to any binary predicate. Since the definite in (25) refers to a non-atomic individual - the group of the two daughters in scenario (22) -, the $\phi$-head above the definite description must contain the [Pl]-feature, which then triggers plural agreement on the noun.

$[\mathrm{Pl}]$ the ([**daughter $]$ of Bill and James)

In this section, I have established that [Pl] on nouns must not be interpretable, which is incompatible with the standard proposal on how number morphology is interpreted.

\section{Quantifiers}

In the two subsequent sections, I investigate how number morphology with other noun phrases can be accounted for on my proposal. In this section, I consider singular universals as in (26). 
a. Every boy is singing.

b. Jeder Junge singt. (German) every boy is singing

On my proposal, quantifiers cannot be interpreted within $\phi \mathrm{P}$ because $\phi$ can only take an argument of type $e$. Therefore, all quantifiers must scope out from the position below $\phi$. I assume that this is done by syntactic movement as in (27):

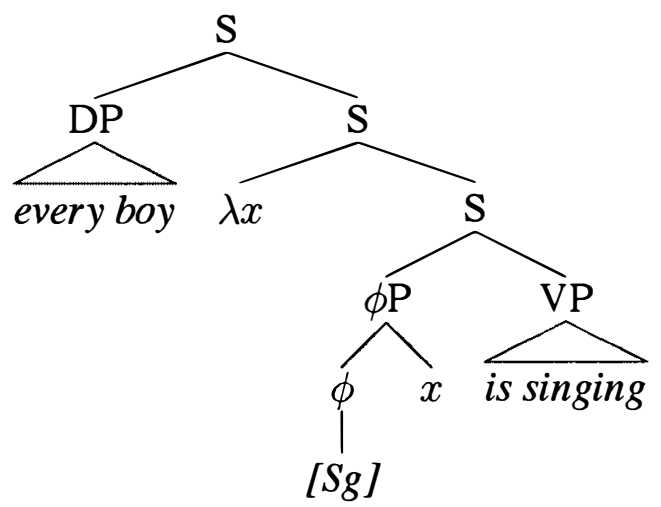

In (26), the presupposition of the [Sg]-feature is projected to the $\lambda$-predicate that forms the scope of the universal. I assume that universal quantifiers project presuppositions from their scope 'universally' as defined in (27), i.e. to each individual that satisfies the restrictor of the universal (Heim 1983).

$$
\operatorname{every}(R)(S) \text { is defined iff. } \forall x: R(x) \rightarrow x \in \operatorname{domain}(S)
$$

I argue below that every must be decomposed into the two morphemes in (30). A consequence of the proposal is that the semantics of every restricts the range of quantification to atomic individuals. It follows that only [Sg] can occur in $\phi$ in (27).

Now consider the cumulative example in (28), which is repeated from (24) above.

(28) Every resident of these cities has a bicycle.

Assume that Amsterdam and Berlin are the two relevant cities, and that $\mathrm{a}_{1}$ and $\mathrm{a}_{2}$ are Amsterdam's residents, while $b_{1}$ and $b_{2}$ are the residents of Berlin. Cumulation of in the NP yields (29).

$$
\begin{aligned}
& \text { ** resident(Amsterdam } \oplus \text { Berlin) }=\left\{\mathrm{a}_{1} \oplus \mathrm{b}_{1}, \mathrm{a}_{2} \oplus \mathrm{b}_{1}, \mathrm{a}_{1} \oplus \mathrm{b}_{2}, \mathrm{a}_{2} \oplus \mathrm{b}_{2}, \mathrm{a}_{1} \oplus \mathrm{a}_{2} \oplus \mathrm{b}_{1},\right. \\
& \left.\mathrm{a}_{1} \oplus \mathrm{a}_{2} \oplus \mathrm{b}_{2}, \mathrm{a}_{1} \oplus \mathrm{b}_{1} \oplus \mathrm{b}_{2}, \mathrm{a}_{2} \oplus \mathrm{b}_{1} \oplus \mathrm{b}_{2}, \mathrm{a}_{1} \oplus \mathrm{a}_{2} \oplus \mathrm{b}_{1} \oplus \mathrm{b}_{2}\right\}
\end{aligned}
$$

Applying a universal quantifier directly to (29) yields an interpretation that is clearly wrong. Namely, it would require every group of individuals listed in (29) to one a bicycle.

I propose therefore to decompose every into two parts definite DER and a quantifier part JE. Applying the definite determiner to (29) yields the maximal group of that set as in (30a). The lexical entry for the universal in (30) then quantifies over the atomic parts of a group individual. 
JE DER resident of these cities

a. $\llbracket$ DER resident of these cities $\rrbracket=\mathrm{a}_{1} \oplus \mathrm{a}_{2} \oplus \mathrm{a}_{3} \oplus \cdots \oplus \mathrm{b}_{1} \oplus \mathrm{b}_{2} \oplus \cdots$

b. $\llbracket \mathrm{JE} \rrbracket(X)(P)$ is defined iff. $\forall x:(\operatorname{atom}(x) \wedge x \sqsubset X) \rightarrow x \in \operatorname{domain}(P)$ where defined: $\llbracket \mathrm{JE} \rrbracket(X)(P)=1$ iff. $\forall x:(\operatorname{atom}(x) \wedge x \sqsubset X) \rightarrow P(x)$

Matthewson (2001) independently proposes the semantics of universal quantifiers in (30) based on evidence from a Salish language. She concludes that her semantics should also be correct for English every, but solely based a principle of semantic uniformity she puts forth. My consideration of cumulative nouns under universals, hence, provides direct empirical evidence for her proposal. A further argument for the proposal is that it predicts the existence presupposition of every.

The Salish language Matthewson discusses differs from English in that the noun head in the complement of a universal quantifier bears plural morphology. This, on my proposal, indicates that in this Salish language a $\phi$-head must occur below $J E$, while in English it occurs only above $J E$.

The need for of $\mathrm{QR}$ of a DP scoping it out of $\phi \mathrm{P}$ argues for my proposal that the interpreted number feature is syntactically separate from D. However the possibility of QR must be blocked with conjunctions and definites: Otherwise QR of a conjunction or definite followed by the insertion of a distributivity operator would predict singular morphology to be compatible with conjunctions and definites. For example, in the representation (31) the [Sg]-feature can be licensed.

[the books] $* \lambda x .([\mathrm{Sg}] x)$ is lying on the table

But, QR of definites and conjunctions is ruled out by Fox's (2000) Scope Economy, since the resulting interpretation would also be available without this instance of QR by applying the ${ }^{*}$-operator to the VP. ${ }^{7} \mathrm{QR}$ of every-DPs, on the other hand, does not violate Scope Economy as it is the only way to generate an interpretable LF-representation.

My proposal entails that any language that has number morphology and quantifiers must allow QR. Therefore, the presence of agreement morphology might serve as a trigger for language learners to acquire quantifier raising. This would explain the contrast between German and Japanese inverse linking constructionsthat German allows inverse linking in (32a), but Japanese in (32b) does not: ${ }^{8}$
a. Ein Koffer von jedem one suitcase of everyone
b. daremo-no kaban-wa everyone-GEN suitcase-TOP

The projection of number presuppositions from the scope of universals provides also a further argument for my claim that $[\mathrm{Pl}]$ is semantically empty. Consider the examples in (33):

(33) a. Every boy should invite his sister.

b. Every boy should invite his sisters. 
The singular (33a) is only acceptable when each of the relevant boys has exactly one sister. The plural (33b), however, is not restricted to situations where each boy has multiple sisters. It can also be used in mixed situations where some of the boys have more than one sister, while the others have only one sister.

This difference between $[\mathrm{Sg}]$ and $[\mathrm{Pl}]$ follows from my proposal. The inherent presupposition of [Sg] projects universally. His sisters in (33b) has an inherent existence presupposition, which again projects universally, but no number presupposition. A further presupposition of [Pl], however, is derived from principle (7) by a computation comparing the presupposition of (33b) with that of (33a). This computation is similar to a proposal I have developed for implicatures (Sauerland $2002 \mathrm{~b}$ ). The result is that the sentence (33b) can be used whenever the presupposition of $(33 a)$ is not satisfied and the inherent existence presupposition is. This predicts that (33b) presupposes that each boy has at least one sister and that at least one boy has two or more sisters.

For reasons of space, I cannot address number marking with Hackl's (2000) comparative quantifiers in detail here. I expect that, once his decomposition approach is adopted, no particular problems arise. The idea would be that (34a) is an indefinite, which the next section covers. (34b), on the other hand, should be analyzed as the number $n$ such that $n$ many books are on the table is 1.0. In this case, the uniqueness presupposition of the singular would render the assertion contingent, which I assume is blocked. ${ }^{9}$
a. One book is on the table.
b. 1.0 books are on the table.

\section{Positive and Negative Indefinites}

The semantics of indefinites and bare plurals is a widely and very controversially discussed topic (Carlson 1977, Wilkinson 1991, Krifka et al. 1995, and others). It seems to me that only some of the proposals for the semantics of indefinites are compatible with my ideas about number, but this is also a question that needs more investigation. The analysis I present in the following assumes with Krifka et al. (1995) that indefinites and bare plurals can both be analyzed as existential quantifiers. ${ }^{10,11}$ If indefinites are existentials, then they must scope out to a position above $\phi \mathrm{P}$ for type reasons just like the universal quantifier in the previous section. Therefore, the number presupposition enters the sentence meaning in the scope of the existential.

Consider first how presuppositions generally are projected from the scope argument of an indefinite. I assume that an existential presupposition projects, as captured by the lexical entry for $a$ in (35) (and similarly for one and some).

$$
\begin{aligned}
& \llbracket \mathrm{a} \rrbracket(R)(S) \text { is defined iff. } \exists x: R(x)=1 \wedge x \in \operatorname{domain}(S) \\
& \text { where defined } \llbracket \mathrm{a} \rrbracket(R)(S)=1 \text { iff. } \exists x: R(x)=1 \wedge S(x)=1
\end{aligned}
$$

Note that the term $S(x)=1$ in line 2 of (35) implies that $x \in \operatorname{domain}(S)$. There- 
fore, a presupposition of $S$ makes a non-trivial contribution to the truth-conditions of an existential statement.

For an illustration, consider (36) from Karttunen and Peters (1979:53). For now, just consider the presupposition of $x$ managed to $Y$ that $Y$ was difficult for $x$. Then, (35) predicts the presupposition that it was difficult for someone to succeed George $\mathrm{V}$-an essentially vacuous presupposition since obtaining the succession was difficult for anybody but the crown-prince. Furthermore, (36) is true if there is someone such that it was hard for him to succeed George $\mathrm{V}$ and he actually did it. ${ }^{12}$

(36) Someone managed to succeed George V on the throne of England.

Now consider the effect of number on an existential. (37) and (38) show a singular and plural sentence with their predicted presupposition and assertion.
a. Lina harvested a tomato.
b. Presupposition: $\exists x$ : atom $(x) \wedge[*$ tomato $](x)$
c. Assertion: $\exists x$ : atom $(x) \wedge[*$ tomato $](x) \wedge$ Lina harvested $x$.
a. Lina harvested tomatoes.
b. Presupposition: $\emptyset$
c. Assertion: $\exists x$ : [*tomato] $(x) \wedge$ Lina harvested $x$

The predictions for (37) are, as far as I can see, accurate. However, the predicted assertion in (38c) is too weak: It is incorrectly true if Lina harvested only one tomato. Here is one way to derive a stronger assertion: Heim's principle (7) predicts that (38a) has (39) as a further presupposition.

$$
\text { Implicated Presupposition: } \neg \exists x \text { : atom }(x) \wedge\left[{ }^{*} \text { tomato }\right](x)
$$

Now apply the reasoning schema $\exists x A(x), \neg \exists x B(x) \models \exists x: A(x) \& \neg B(x)$ to (38c) and (39). The result in (40) is the desired stronger assertion with $\neg$ atomic $(x)$ in the scope of the existential.

$$
\exists x:[* \text { tomato }](x) \wedge \text { Lina harvested } x \wedge \neg \operatorname{atomic}(x)
$$

This line of reasoning must proceed without taking the distributivity of the predicate tomato into account $(\exists x \operatorname{tomato}(x) \rightarrow \exists x$ : tomato $(x) \wedge$ atomic $(x))$. I assume this is done only later, at which point (39) is canceled because it contradicts the assertion (38c). Crucially though, the strengthened assertion (40) can remain.

My reason for this derivation of (40) are negated indefinites. Negated indefinites have been used by a number of people including Schwarzschild (1996) to argue for the weak semantics of the plural that, in a different way, I advocate as well. A case in point is the fact that the plural examples in (41b) entail the singular examples in (41a). (I assume that 'no' is decomposed into sentential negation and an indefinite (Penka 2002).)

(41) a. Lina didn't harvest a tomato. / Lina harvested no tomato.

b. Lina didn't harvest tomatoes. / Lina harvested no tomatoes. 
The entailment from (41b) to (41a) would be blocked if $\neg$ atomic $(x)$ was added to the assertion of $(41 \mathrm{~b})$ in the scope of the existential. But, a derivation along the lines of (40) is blocked in this case: The two premises of the derivation of (40) were the presupposition of the singular example, and the assertion of the plural example. Consider these two parts of the analysis of (41):
a. Presupposition of (41a): $\exists x:$ atom $(x) \wedge$ [*tomato] $(x)$
b. Assertion of (41b): $\neg \exists x$ : [*tomato] $(x) \wedge$ Lina harvested $x$

Because the assertion is negated while the presupposition is not, an entailment analogous to (40) cannot be drawn from (42). Therefore, (42b) is predicted to entail (42a).

\section{Other Agreement Features}

I believe my proposal can be extended to other agreement features. Consider first person agreement with coordinations in German:
a. Ich und Du sollten uns gegenseitig helfen.
I and you should-1st-Pl us mutually help
b. Du und Tina solltet euch gegenseitig helfen. You and Tina should-2nd-Pl you mutually help
c. Tina und Tom sollten sich gegenseitig helfen. Tina and Tom should self mutually help

The agreement morphology of the verb in (43) is determined by the entire coordination, not just by one of the coordinated forms. This is expected if the $\phi$-head above the coordination also must contain a Person feature. The lexical entries of the person features in (44) then predict the data in (43):
a. $\llbracket 1 \mathrm{st} \rrbracket=\mathrm{id}_{\{x \mid \text { speaker } \cap x \neq \emptyset\}}$
b. $\llbracket 2 \mathrm{nd} \rrbracket=\mathrm{id}_{\{x \mid \text { participants } \cap x \neq \emptyset\}}$
c. $\llbracket 3 \mathrm{rd} \rrbracket=\mathrm{id}_{\mathrm{D}_{\mathrm{e}}}$

Gender in Czech shows the same regularity. Consider the facts in (45) (Vanek 1977:31). These follow if masculine gender is vacuous, feminine presupposes non-masculinity, and neuter presupposes genderlessness.
a. Jan a Petr šli do biografu
Jan and Peter went-masc-pl to the movies
b. Věra a Barbara šly do biografu Vera and Barbara went-fem-pl to the movies
c. Jan a Věra šli/*šly do biografu Jan and Vera went-masc-pl to the movies
d. Matka a její dítě šly do biografu Mother and her child-neut went-fem-pl to the movies


e. Otec a jeho dítě-neut šli do biografu

Father and his child went-masc-pl to the movies

\section{The Feature-Subset Principle}

I have always given an empty semantics for one of the features. In fact, I would like to postulate the general principle.

(46) If $F_{1}$ and $F_{2}$ are two presuppositional features that can be inserted in the same syntactic position, then they must stand in a subset relationship (i.e. $\operatorname{domain}\left(\mathrm{F}_{1}\right) \subset \operatorname{domain}\left(\mathrm{F}_{2}\right)$ or domain $\left.\left(\mathrm{F}_{2}\right) \subset \operatorname{domain}\left(\mathrm{F}_{1}\right)\right)$.

I have given three arguments for the weak semantics of the plural that is entailed by (46): ${ }^{13}$ the use of plural pronouns for politely addressing a singular person in various languages in Section 2.2, the weak existential presupposition of the plural in the scope of a universal in Section 4, and the entailment from plural negated indefinites to the singular in 5. Of these three arguments, the first one can also be used to argue for the weak semantics of third person, since in languages like German as third person form is used instead of you for a polite address. The argument from presupposition projection with universals can be used widely to find support for principle (46). In (47), I give examples from the non-participant presupposition of third Person, the non-past presupposition of the present tense, and the anti-uniqueness presupposition of the indefinite (Heim 1991). ${ }^{14}$
a. Everyone of us should remember that he is partially responsible .
b. Every Sunday, John fasts. (Sauerland 2002a)
c. Every candidate should sent a paper of his.

\section{Conclusion}

My main claim in this paper was that the treatment of plurality requires a presuppositional account of agreement. I have shown in Section 2 that such presuppositional account is necessary for coordinations and pronouns. In Section 3, I have shown that my account also is the only one that can explain the number marking on definite descriptions. These two arguments are then the arguments for my claim.

I hope to have shown in section 4 through 7 that the semantic licensing account of agreement raises interesting semantic questions about the interaction of presuppositions and implicatures. In particular, the facts with indefinites in section 5 are still puzzling to me.

\section{Endnotes}

${ }^{*}$ This material developed through presentations at the Semantics Reading Group 
in Northampton, Massachusetts, the Universität Stuttgart, the University of Pennsylvania, the University of Delaware, the SALT 13 conference at the University of Washington in Seattle, and the Zentrum für allgemeine Sprachwissenschaft in Berlin. I would like to thank the audiences at these events for their many helpf ul comments, as well as Irene Heim, Ji-Yung Kim, Tilman Berger, Tom Roeper, and Ede Zimmermann for further helpful comments. The German Research Council is currently funding me as an Emmy-Noether-Fellow (Grant SA 925/1-1), which I gratefully acknowledge.

${ }^{1}$ Dowty and Jacobson (1989) propose that singular verb morphology be interpreted as a presupposition that the argument of the verb be atomic, and the plural as a complementray non-atomicity presupposition. The proposal, however, seems to run afoul examples where the subject is plural, but receives a distributive interpretation. (i) is a particular dramatic case of this:

(i) They each believe that they are the only person in the room.

Kerstin Schwabe (p.c.) points out though that the possibility of (optional) plural agreement in German leftward gapping, as in (ii), might provide an argument for semantic licensing of verbal agreement (Schwabe and von Heusinger 2001). However, the syntactic struture of such examples is far from clear.

..., weil er ein Buch und sie eine DVD gekauft hat/haben.

$\ldots$, because he a book and she a DVD bought has/have

${ }^{2}$ I assume a standard mereological ontology for groups as, for example, that of Schwarzschild (1996). The domain of individuals contains both single individuals and groups of individuals. I use $\oplus$ to indicate the mereological sum, and $\sqsubseteq$ to indicate the part-of relationship.

${ }^{3}$ Since what is a single individual in one world, can have a plural counterpart in another, the number morpheme must also have a world argument position. The examples in (i) show that the world argument position of the number morpheme must be covalued with the world argument position of the noun it immediately ccommands:

(i) Scenario: Kai hears noises from the basement and assumes that there are two monsters in the basement. Actually, his mother is down there making the noises.
a. Kai believes the monsters are dangerous.
b. Kai believes his mother is dangerous.
c. ${ }^{*}$ Kai believes the monster is dangerous.
d. ${ }^{*}$ Kai believes his mothers are dangerous.

${ }^{4}$ I focus here on DP coordinations which provide a direct argument for my approach. See Heycock and Zamparelli (2003) for a recent investigation into coordination below DP. Peter Staudacher (p.c.) pointed out example (i) to me which seems to be a DP coordination, but is nevertheless beyond the scope of this paper. 
(i) Every boy and every girl who met each other at the station went out.

${ }^{5}$ I assume with Heim (1994) and others, that agreement features on bound pronouns are not interpreted because of examples such as (i) in footnote (ii).

${ }^{6}$ Chierchia (1998b) proposes a definition of the ${ }^{*}$-operator that excludes atomic individuals from the resulting set. The argument I develop below against the standard approach also argues Chierchia's version of it. Furthermore, I show in sections 2.2 and 7 that generally the plural must include the singular.

${ }^{7}$ Examples like (i) marginally allow a construal where the object takes distributive wide scope over the subject, which is possibly the result of QR of the object. But, a pronoun bound by the object must bear plural agreement indicating the John and Bill must bear the [Pl]-feature.

(i) Someone told [John and Bill $]_{\mathrm{i}}$ about the things their $\mathrm{r}_{\mathrm{i}} /$ his $_{\mathrm{i}}$ son had said.

If this description is correct, it shows that, though $\mathrm{QR}$ of the object seems to be possible, $[\mathrm{Sg}]$ is still not licensed. This though is also predicted by Fox's condition because $\mathrm{QR}$ of $\phi \mathrm{P}$ and $\mathrm{QR}$ of DP result in the same interpretation, but $\mathrm{QR}$ of $\phi \mathrm{P}$ is shorter and hence preferred by his economy condition. Licensing of [Sg], however, is only possible if DP QRs.

${ }^{8}$ Penka Stateva (p.c.) points out that Japanese does allow non-surface scope of the superlative morpheme. Hence, it seems that only the availability of QR of DPs in a language must be triggered by the presence of overt agreement.

${ }^{9}$ Here are some more puzzling facts that various people have pointed out to me. In Turkish and Hungarian cardinals generally trigger singular agreement. In German, only cardinals that end in one trigger singular agreement. While I have at present nothing to say about the former, observe that, in German, actually the numerals ending in one actually only trigger singular agreement when not the numeral eins ('one'), but the indefinite ein ('a') is used as shown by (i). I propose that 'tausendundeine Nacht' must be derived by NP ellipsis from 'tausend Nächte und eine Nacht'.
a. Tausendundeine Nacht ist/sind vergangen. thousand-and-a nights is/are passed
b. Tausendundeins Nächte *ist/sind vergangen. thousand-and-one nights $*$ is/are passed

${ }^{10}$ I leave predicative indefinites for future research. Example (i) shows that number is not predicted by subject-predicate agreement with predicative indefinites.

(i) Kai and Lina both believe that they are a tiger.

${ }^{11}$ English is one of the languages that allows bare plurals as the argument of kind predicates (see (a)), though other indefinites cannot occur there (see (ib)). If bare nouns are kind denoting, there is still a question why these kinds are plural while (ic) requires singular.

(i) a. Neanderthals are extinct. 
b. \#Some Neanderthals are extinct.

c. The Neanderthal is extinct.

Possibly, bare plural kinds are derived by a kind-formation operator that applies to $\phi \mathrm{P}$ (cf. Chierchia 1998a).

${ }^{12}$ The account here hence avoids the 'requantification' problem Karttunen and Peters (1979) discuss. It would interesting to investigate whether a similar account can be given for the requantification problem of von Fintel (1995) in focus semantics. He points out that standard focus semantics predicts for examples like (i) a wrong interpretation that can be paraphrased as: 'Whenever property owners do something to a trespasser, property owners shoot at a (possibly different) trespasser.'

In the US, property owners always shoot at a trespasser.

Von Fintel presents a situation semantic solution for the problem, but an alternative account based on a presuppositional semantics of focus might be possible.

${ }^{13}$ (47) would also be satisfied if [Sg] was semantically vacuous, and [Pl] contentful. It is an empirical fact that $[\mathrm{Pl}]$ is semantically unmarked. Interestingly, morphologically $[\mathrm{Sg}]$ seems to be unmarked.

${ }^{14}$ For (48c) consider this scenario: Several candidates applied. Some have written only one paper, others have written more than one. The selection committee decides ... While (48c) is acceptable, (i) is not:

(i) \#Every candidate should sent the paper of his.

\section{References}

Beck, Sigrid. 2000. Star Operators. Episode One: Defense of the Double Star. In UMOP 23: Issues in Semantics, ed. by K. Kusumoto and E. Villalta, 1-23. Amherst: GLSA, University of Massachusetts.

--, and Uli Sauerland. 2000. Cumulativity is needed: A reply to Winter (2000). Natural Language Semantics 8.349-371.

Bennett, Michael. 1974. Some extensions of a Montague fragment of English. Ph.D. dissertation, UCLA.

Carlson, Greg N. 1977. Reference to kinds in English. Ph.D. dissertation, University of Massachusetts, Amherst.

Chierchia, Gennaro. 1998a. Reference to kinds across languages. Natural Language Semantics 6.339-405.

--. 1998b. Plurality of mass nouns and the notion of "semantic parameter". In Events and Grammar, ed. by S. Rothstein, 53-103. Dordrecht, Netherlands: Kluwer.

Cooper, Robin. 1983. Quantification and syntactic theory. Dordrecht, Netherlands: Reidel.

Dowty, David, and Pauline Jacobson. 1989. Agreement as a semantic phenomenon. In Proceedings of the Fifth Eastern States Conference on Linguistics (ESCOL '88), ed. by J. Powers and K. de Jong, 95-101. Ithaca, N.Y., Cornell University, CLC Publications.

Fox, Danny. 2000. Economy and semantic interpretation. Cambridge, Mass.: MIT Press. 
Hackl, Martin. 2000. Comparative Quantifiers. Ph.D. dissertation, Massachusetts Institute of Technology, Cambridge, Mass.

Head, Brian. 1978. Respect Degrees in Pronominal Reference. In Universals of Human Language, Volume 3, ed. by J. Greenberg, C. Ferguson, and E. Moravcsik, 151211. Stanford: Stanford University Press.

Heim, Irene. 1983. On the projection problem for presuppositions. In Proceedings of WCCFL 2, ed. by D. Flickinger, 114-125. Stanford, Calif., CSLI.

-_. 1991. Artikel und Definitheit (Articles and definiteness). In Semantik: Ein internationales Handbuch der zeitgenössischen Forschung, ed. by A. von Stechow and D. Wunderlich, 487-535. Berlin: de Gruyter.

- - 1994. Puzzling reflexive pronouns in de se reports. Unpublished Handout (Presented at Bielefeld), MIT.

Heycock, Caroline, and Roberto Zamparelli. 2003. Friends and colleagues: Plurality, coordination, and the structure of DP. unpublished manuscript, University of Edinburgh and Universitá di Bergamo.

Karttunen, Lauri, and Stanley Peters. 1979. Conventional Implicature. In Presupposition, ed. by C. Oh and D. Dinneen, volume 11 of Syntax and Semantics, 1-56. New York: Academic Press.

Krifka, Manf red. 1986. Nominalreferenz und Zeitkonstitution: Zur Semantik von Massentermen, Pluraltermen und Aspektklassen. Ph.D. dissertation, Munich University, Munich, Germany.

- , and others. 1995. Genericity: An introduction. In The Generic Book, ed. by G. Carlson and J. Pelletier, Chicago, Ill.: University of Chicago Press.

Link, Godehard. 1983. The logical analysis of plurals and mass terms: A lattice theoretical approach. In Meaning, Use, and the Inter pretation of Language, ed. by R. Bäuerle, C. Schwarze, and A. von Stechow, 302-323. Berlin: de Gruyter.

Matthewson, Lisa. 2001. Quantification and the nature of crosslinguistic variation. Natural Language Semantics 9.145-189.

Penka, Doris. 2002. Zur Semantik der negativen Indefinita im Deutschen. TübingenLinguistik-Report Nr. 1, Universität Tübingen.

Sauerland, Uli. 2002a. The present tense is vacuous. Snippets 6.

- . 2002b. Scalar implicatures in complex sentences. (to appear in Linguistics and Philosophy in a revised form).

Schwabe, Kerstin, and Klaus von Heusinger. 2001. On shared indefinite NPs in coordinative structures. Journal of Semantics 18.243-269.

Schwarzschild, Roger. 1996. Pluralities. Dordrecht, Netherlands: Kluwer.

Sternef eld, Wolfgang. 1998. Reciprocity and cumulative predication. Natural Language Semantics 6.303-337.

Vanek, Anthony L. 1977. Aspects of Subject-Verb Agreement. Edmonton, Canada: Linguistic Research.

Verkuyl, Henk. 1981. Numerals and quantifiers in X-bar syntax and their semantic interpretation. In Formal Methods in the Study of Language 2, ed. by J. Groenendijk, T. Janssen, and M. Stokhof, 567-599. Amsterdam: MCT.

von Fintel, Kai. 1995. A minimal theory of adverbial quantification. draft, MIT.

Wilkinson, Karina. 1991. Studies in the semantics of generic noun phrases. Ph.D. dissertation, University of Massachusetts, Amherst. 